\title{
Renal Colic by Gastrointestinal Perforation: Endoscopic Approach
}

\author{
Joana Raquel Rodrigues Gaspar ${ }^{\mathrm{a}}$ Eunice Vieira e Monteiro ${ }^{\mathrm{a}}$ \\ Vítor José Costa Simões ${ }^{a}$ Paulo Sérgio Durão Salgueiro ${ }^{b}$ \\ ${ }^{a}$ Department of Surgery, General Surgery, Centro Hospitalar e Universitário do Porto-Hospital de Santo António, \\ Porto, Portugal; ${ }^{b}$ Gastroenterology, Department of Medicine, Centro Hospitalar e Universitário do Porto, Porto, Portugal
}

\section{Keywords}

Duodenal perforation $\cdot$ Foreign body $\cdot$ Fishbone $\cdot$ Renal colic

\section{Cólica renal por perfuração gastrointestinal:} abordagem endoscópica

\section{Palavras Chave}

Perfuração duodenal · Corpo estranho - Espinha de peixe · Cólica renal

Most cases of acute, sharp, flank pain radiating to the scrotum or groin are caused by nephrolithiasis or ure- terolithiasis and are commonly referred to as renal colic. Computed tomography (CT) has become a standard imaging technique for uncomplicated renal colic in many countries [1], revealing an alternative diagnosis in up to $6 \%$ of the patients [1].

Although rare, gastrointestinal perforation by a foreign body may be associated with hydronephrosis, due to the contiguous inflammatory process, and present itself as flank pain [2]. Fishbone ingestion with bowel perforation is a particularly challenging diagnosis as the presentation may mimic common abdominal pathologies, and patients may not recall the ingestion of a foreign body [3].

The following case highlights the diagnostic difficulties in considering and identifying alternative etiologies
Fig. 1. CT scan showing a foreign body perforating the third portion of the duodenum and crossing the ureter and the psoas muscle (arrow), resulting in hydronephrosis (asterisk). a Axial reconstruction; b sagittal reconstruction.
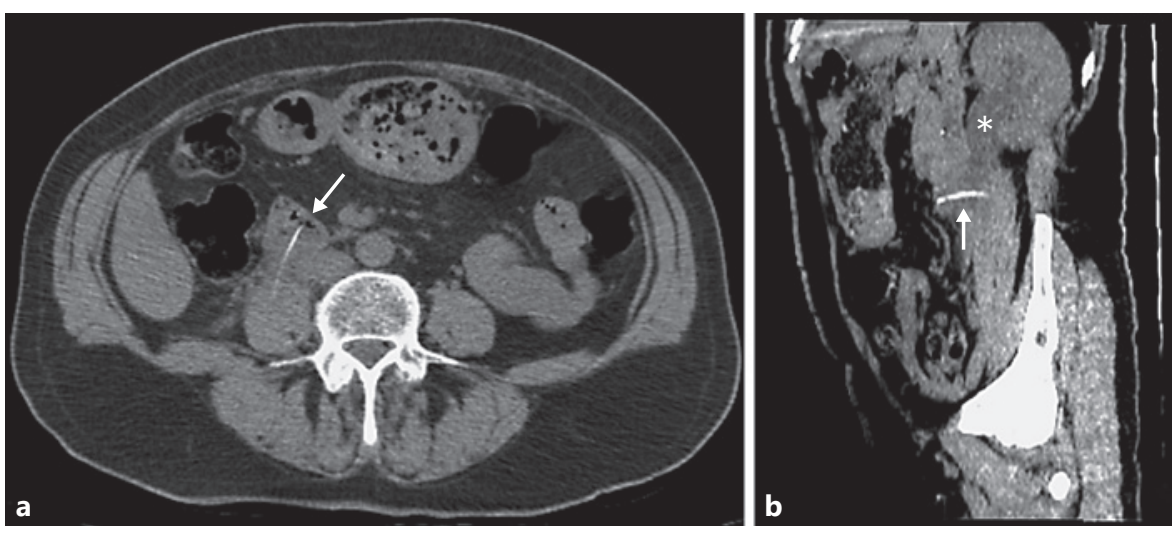

\section{(c) 2020 Sociedade Portuguesa de Gastrenterologia} Published by S. Karger AG, Basel

This article is licensed under the Creative Commons AttributionNonCommercial-NoDerivatives 4.0 International License (CC BY NC-ND) (http://www.karger.com/Services/OpenAccessLicense). Usage and distribution for commercial purposes as well as any distribution of modified material requires written permission.
Joana Raquel Rodrigues Gaspar, Departamento de Cirurgia

Centro Hospitalar e Universitário do Porto-Hospital de Santo António Largo Professor Abel Salazar

PT-4099-001 Porto (Portugal) u11620@chporto.min-saude.pt 
for flank pain and its possible association with gastrointestinal perforation by a foreign body.

The authors present a case of a 63-year-old woman admitted to the emergency room department with a constant, sharp, right flank pain lasting for a week. No urinary, gastrointestinal, or constitutional symptoms were present. On physical examination, the right renal murphy sign was present with no other abnormal findings.

The only laboratory finding was an elevated C-reactive protein $(76.58 \mathrm{mg} / \mathrm{L})$. Renal ultrasound demonstrated renal pelvis dilation but showed no nephrolithiasis or other causes of obstruction. A CT scan without contrast revealed a foreign body intersecting the third portion of the duodenum, the ureter, and the psoas muscle, associated with dilation of the proximal ureter and renal pelvis and densification of the surrounding fat (Fig. 1a, b).
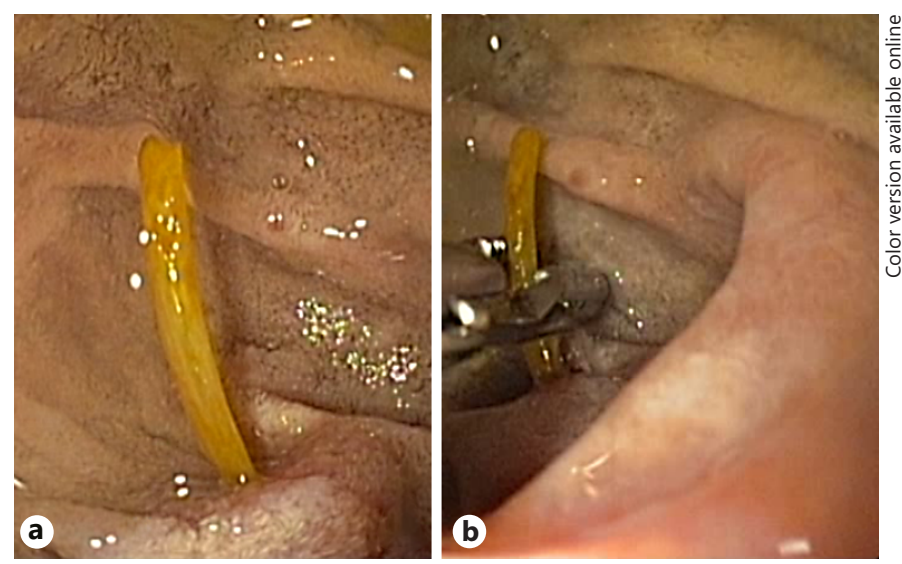

Fig. 2. Esophagogastroduodenoscopy images showing a foreign body (fishbone) embedded in the duodenum wall (a) and its' removal with a foreign body forceps (b).
An esophagogastroduodenoscopy was performed for diagnostic and therapeutic purposes. During the procedure, a fishbone embedded in the wall of the third portion of the duodenum was identified and removed with a foreign body forceps (Fig. 2a, b).

Following the procedure, the patient started intravenous antibiotics and fluids. Oral feeding was reintroduced after 2 days. She was discharged completely asymptomatic after 7 days.

At the 3-month follow-up, the review CT scan with contrast showed complete resolution of the previously observed pathological findings and normal excretion of contrast by the right kidney (Fig. 3a, b).

Gastrointestinal perforation by a foreign body may present itself in various forms, some of which may be difficult to diagnose. CT continues to be the gold standard for diagnosis of the etiology of renal colic.

\section{Statement of Ethics}

The patient has given written informed consent for publication of this clinical case.

\section{Conflict of Interest Statement}

None of the authors has an actual or potential conflict of interest (including financial, consultant or institutional) to declare.

\section{Author Contributions}

J.R.R.G., MD: design of the manuscript, research, manuscript revision, and approval; E.V.M., MD: analysis, revision, and approval; V.J.C.S., MD: analysis, revision, and approval; P.S.D.S., $\mathrm{MD}$ : analysis, revision, and approval.
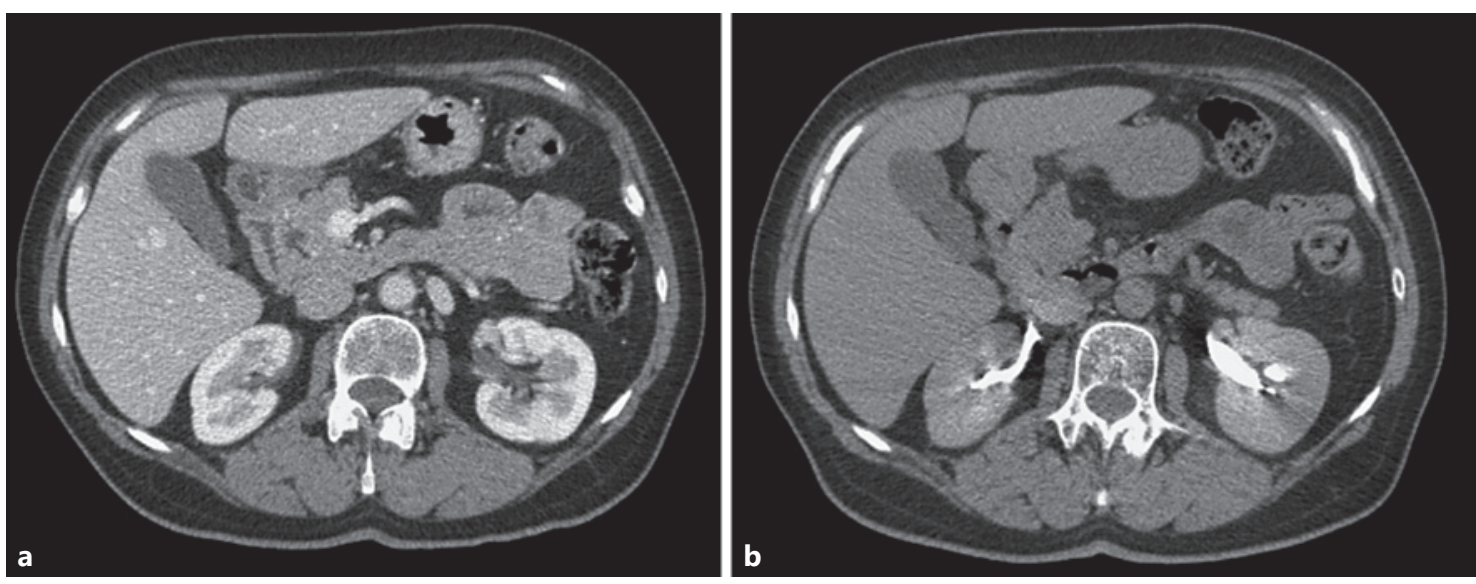

Fig. 3. CT scan (axial reconstruction) showing normal contrast uptake (a) and excretion (b) by the right kidney. 
References
1 Pernet J, Abergel S, Parra J, Ayed A, Bokobza J, Renard-Penna R, et al. Prevalence of alternative diagnoses in patients with suspected uncomplicated renal colic undergoing computed tomography: a prospective study. CJEM. 2015 Jan;17(1):67-73.
2 Nigri GR, Di Giulio E, Di Nardo R, Pezzoli F, D’Angelo F, Aurello P, et al. Duodenal perforation and right hydronephrosis due to toothpick ingestion. J Emerg Med. 2008 Jan;34(1):55-7.

3 Beecher SM, O'Leary DP, McLaughlin R. Diagnostic dilemmas due to fish bone ingestion: case report \& literature review. Int J Surg Case Rep. 2015;13:112-5. 